\title{
Sox2 acts as a rheostat of epithelial to mesenchymal transition during neural crest development
}

\author{
Nikolaos Mandalos ${ }^{1}$, Muriel Rhinn ${ }^{2}$, Zoraide Granchi ${ }^{3}$, loannis Karampelas ${ }^{1,4}$, Thimios Mitsiadis ${ }^{3}$, \\ Aris N. Economides ${ }^{5}$, Pascal Dollé ${ }^{2}$ and Eumorphia Remboutsika ${ }^{*}$ \\ 1 Stem Cell Biology Laboratory, Division of Molecular Biology and Genetics, Biomedical Sciences Research Centre "Alexander Fleming," Vari-Attica, Greece \\ 2 Institut de Génétique et de Biologie Moléculaire et Cellulaire, INSERM, U964, CNRS, UMR7104, Université de Strasbourg, IIIkirch, France \\ ${ }^{3}$ Orofacial Development and Regeneration Unit, Faculty of Medicine, Institute of Oral Biology, University of Zurich, ZZM, Zurich, Switzerland \\ ${ }^{4}$ Department of Neurosurgery, University Hospitals Case Medical Center, Cleveland, OH, USA \\ ${ }^{5}$ Regeneron Pharmaceuticals, Tarrytown, New York, NY, USA
}

\section{Edited by:}

Gianpaolo Papaccio, Second

University of Naples, Italy

\section{Reviewed by:}

Petros Papagerakis, University of Michigan, USA

Virginia Tirino, Department of

Experimental Medicine, Italy

\section{*Correspondence:}

Eumorphia Remboutsika, Stem Cell

Biology Laboratory, Division of

Molecular Biology and Genetics,

Biomedical Sciences Research

Centre "Alexander Fleming,"

34 Fleming Str., 16672 Vari, Attica,

Greece

e-mail: remboutsika@gmail.com

www.eumorphiaremboutsika.com
Precise control of self-renewal and differentiation of progenitor cells into the cranial neural crest (CNC) pool ensures proper head development, guided by signaling pathways such as BMPs, FGFs, Shh and Notch. Here, we show that murine Sox2 plays an essential role in controlling progenitor cell behavior during craniofacial development. A "Conditional by Inversion" Sox2 allele (Sox2COIN) has been employed to generate an epiblast ablation of Sox2 function (Sox2Ep/NV). Sox2 Ep/NV/+(H) haploinsufficient and conditional (Sox2 $2^{E p / N V / m o s a i c}$ ) mutant embryos proceed beyond gastrulation and die around E11. These mutant embryos exhibit severe anterior malformations, with hydrocephaly and frontonasal truncations, which could be attributed to the deregulation of CNC progenitor cells during their epithelial to mesenchymal transition. This irregularity results in an exacerbated and aberrant migration of Sox $10^{+}$NCC in the branchial arches and frontonasal process of the Sox2 mutant embryos. These results suggest a novel role for Sox2 as a regulator of the epithelial to mesenchymal transitions (EMT) that are important for the cell flow in the developing head.

Keywords: Sox genes, SoxB, neurocristopathies, craniofacial development, stem cells, neural progenitors, heterochrony

\section{INTRODUCTION}

The head develops from anteriorly located cells of the epiblast. These cells form the neuroectoderm that gives rise to the brain and craniofacial structures stemming via epithelial to mesenchymal transitions (EMT). Balanced control between self-renewal of neural progenitors and their differentiation into cranial neural crest cells (NCCs) ensures proper head development. Cranial NCCs (CNCCs) arise from a NCC pool derived from the neural ectoderm, and give rise to most of the peripheral nervous system and craniofacial structures. NCCs are induced by interactions between the neuroectoderm and adjacent non-neural ectoderm (Dickinson et al., 1995; Selleck and Bronner-Fraser, 1995). These interactions are orchestrated by a combination of signaling molecules such as Wnt proteins, bone morphogenetic proteins (BMPs) (Liem et al., 1995), fibroblast growth factors (FGFs), retinoic acid and proteins of the Notch pathway (Labonne and Bronner-Fraser, 1998; Aybar et al., 2002; Aybar and Mayor, 2002; Christiansen et al., 2002; Endo et al., 2002; Garcia-Castro et al., 2002; Villanueva et al., 2002; Wu et al., 2003). NCCs delaminate from the dorsal neural tube, migrate along defined territories of the craniofacial complex and finally differentiate into many cell types, including neurons, glial cells, Schwann cells, melanocytes, and cells of the connective tissue (Ayer-Le Lievre and Le Douarin, 1982).
Neural crest (NC) development depends on the activation of NCC-specific genes at the neural plate border (Gammill and Bronner-Fraser, 2003; Heeg-Truesdell and Labonne, 2004; Huang and Saint-Jeannet, 2004). A number of these genes belong to the Sox (Sry HMG-box) family of transcription factors (subdivided into $\mathrm{A}-\mathrm{H}$ groups) harboring an HMG-box as a DNA binding domain (Pevny and Lovell-Badge, 1997; Wegner, 1999; Wilson and Koopman, 2002; Bernard and Harley, 2010; Kamachi et al., 2013; Karnavas et al., 2013). Whereas all SoxE genes show expression in NCC progenitors at some point following NC induction, differences exist in the onset and sequence of events. Induction of NCC formation is triggered by the expression of SoxE genes (Gammill and Bronner-Fraser, 2002), such as Sox8, Sox9, and Sox10 (Bowles et al., 2000). These genes are already expressed in all premigratory NCCs, while later their expression becomes restricted to distinct NCC-derived subpopulations (Stolt et al., 2004; Betancur et al., 2011). Sox8 expression occurs before NCC migration from the neural tube, followed by Sox9, and shortly after Sox10 (Cheng et al., 2000). Sox9 expression overlaps with that of a number of NCC determinant genes, such as FoxD3, Bmp4, cadherin 6b, Slug, and RhoB (Liu and Jessell, 1998; Briscoe et al., 2003). BMP signaling drives the induction, formation, determination and migration of CNCCs (Nie et al., 2006). Cadherin $6 \mathrm{~b}$ establishes the premigratory NCC domain in the neural tube (Taneyhill, 2008). Slug induces premigratory 
and migratory CNCC behavior (Del Barrio and Nieto, 2002). Foxd3 induces the segregation of NCC from the neural tube (Kos et al., 2001). Rho is involved in delamination of NCC from the dorsal neural tube (Rutishauser and Jessell, 1988; Cordero et al., 2011). As migration starts (Nakagawa and Takeichi, 1995; Jessel and Weiss, 1998), Slug, RhoB, N-cadherin, and cadherin 6b are down-regulated at the trunk level (Akitaya and Bronner-Fraser, 1992; Monier, 1995), while FoxD3 expression persists in all migratory NCCs (Cheng et al., 2000; Dottori et al., 2001). On the other hand, Sox 10 persists only in the trunk NCC populations (Cheng et al., 2000; Remboutsika et al., 2011).

Amongst SoxB genes (Sox1,2,3,14, and 21), Sox2 has been reported to play a cell-autonomous role in NCC development (Pan and Schultz, 2011). Sox2 is one of the early-activated genes in the developing neural plate (Graham et al., 2003; Wen et al., 2008; Hutton and Pevny, 2011), and its expression is reduced in the dorsal neural tube as NCCs segregate and migrate. Thereafter, Sox2 expression is upregulated in a subset of cells that arrived at their final destination, and gradually becomes restricted to the glial sublineages (Aquino et al., 2006). Sox2 prevents terminal differentiation of Schwann cells (Wakamatsu et al., 2004; Le et al., 2005) and represses the melanocyte fate (Laga et al., 2010). Ectopic expression of Sox 2 in embryonic ectoderm and neural plate explants reveals that Sox2 is sufficient to inhibit NCC formation both in chick and mouse embryos (Papanayotou et al., 2008; Remboutsika et al., 2011). It has been postulated that Sox2 counteracts NC development (Scherson et al., 1993; Placzek and Briscoe, 2005; Remboutsika et al., 2011), as the NCC marker Slug is only expressed at regions of low Sox2 expression in premigratory and migratory NCCs (Wakamatsu et al., 2004). Despite evidence that points to an involvement for Sox2 in multiple steps of NCC development in mouse embryo, its role is yet elusive.

Homozygous Sox2-null mouse embryos die around implantation (Avilion et al., 2003b; Mandalos et al., 2012). We have developed a conditional ablation strategy, using a "Conditional by Inversion" Sox2 allele (Sox2 ${ }^{\text {COIN }}$ ) (Mandalos et al., 2012), in order to study the role of Sox2 in epiblast-derived multipotent lineages. Here, we show that Sox 2 plays an essential role in controlling the behavior of the progenitor cells during head development. EMT is affected in mutant embryos during CNCC development, resulting in hydrocephaly and frontonasal defects. These results suggest a novel role for Sox2 as a rheostat of the EMTs that influence head development in mice.

\section{MATERIALS AND METHODS \\ EXPERIMENTAL ANIMALS}

Generation of Sox $2^{\text {COIN }}$ mice was described elsewhere (Mandalos et al., 2012). All animals were handled in strict accordance with good animal practice as defined by the Animals Act 160/03.05.1991 applicable in Greece, revised according to the 86/609/EEC/24.11.1986 EU directive regarding the proper care and use of laboratory animals and in accordance to the Hellenic License for Animal Experimentation at the BSRC "Alexander Fleming" (Prot. No. 767/28.02.07) issued after protocol approval by the Animal Research Committee of the BSRC "Alexander Fleming" (Prot. No. 2762/03.08.05).

\section{GENOTYPING}

Tail, yolk sack or embryonic tissues were isolated and processed according to previously described methodology (Mandalos et al., 2012). PCR amplification conditions and primers used are described elsewhere (Mandalos et al., 2012).

\section{EMBRYO PROCESSING AND HISTOLOGICAL ANALYSIS}

For staging of the embryos, midday of the vaginal plug was considered as embryonic day 0.5 (E0.5). All embryos were harvested in cold $0.12 \mathrm{M}$ phosphate-buffered saline (PBS, $\mathrm{pH} 7.5$ ). For histological analysis, embryos were fixed with $10 \%$ formalin for $24 \mathrm{~h}$ at room temperature and then washed several times with PBS, placed in embedding cassettes and sectioned in a Leica RM2125RT microtome. Paraffin sections $(10 \mu \mathrm{m})$ were stained with hematoxylin and eosin and mounted with xylene based mounting medium, according to standard procedures (Fischer et al., 2008; Cardiff et al., 2014).

Embryos were harvested and fixed with $4 \%$ paraformaldehyde (PFA) in PBS overnight at $4^{\circ} \mathrm{C}$ and thoroughly washed with PBS. Fixed embryos were incubated with $20 \%$ sucrose overnight at $4^{\circ} \mathrm{C}$ for cryoprotection before they were embedded with O.C.T. compound (VWR International), snap-frozen in dry ice and stored at $-80^{\circ} \mathrm{C}$. Sagittal sections were prepared using a Leica cryostat. Cryosections $(10-12 \mu \mathrm{m})$ were collected on Superfrost Plus microscope slides (VWR International) and stored at $-20^{\circ} \mathrm{C}$ before analysis. For in situ hybridization, embryos were fixed overnight in PFA 4\% in PBS then rinsed three times in PBS/Tween $(0.1 \%)$ followed by three times wash in methanol before storage at $-20^{\circ}$. Conventional bright field and fluorescence microscopy was performed under a Leica MZ16FA stereoscope.

\section{RNA IN SITU HYBRIDIZATION}

RNA probes for in situ hybridization reactions were prepared by in vitro transcription as previously described (Knuchel et al., 2000; Chotteau-Lelievre et al., 2006; Rhinn et al., 2011) The probes used were: Hoxa2 and Hoxb1, kindly provided by Robb Krumlauf; Sox2, kindly provided by Robin Lovell-Badge; Sox10, kindly provided by Benoît de Crombrugghe. Whole-mount in situ hybridization (ISH) was performed using an Intavis InSituPro robot (detailed protocol available at http://empress.har.mrc.ac. $\mathrm{uk} /$, gene expression section).

\section{IMAGE ANALYSIS}

Embryo dissections, conventional bright field and fluorescence microscopy were performed under a Leica MZ16FA stereoscope, equipped with a Leica 350 camera and Leica Software. Sections were photographed under a Leica M420 macroscope and DMLB/DM4000B microscopes equipped with Photometrics digital cameras and the CoolSnap imaging software (Roger Scientific).

\section{RESULTS}

\section{EPIBLAST DELETION OF SOX2 RESULTS INTO LETHALITY AROUND E11}

The epiblast is destined to derive all multipotent lineages in the mouse embryo. Previously generated, null alleles of Sox2 $\left(\mathrm{Sox}_{2}^{\beta g e o / \beta g e o}\right.$ and $\left.\mathrm{Sox}_{2}{ }^{\beta \mathrm{geo} 2 / \beta g e o 2}\right)$ are responsible for an early 
embryonic lethal phenotype (Avilion et al., 2003a; Ekonomou et al., 2005), masking any subsequent role of Sox2 in the generation of epiblast-derived multipotent lineages during development. Taking into account the challenges of the Sox 2 locus, in that its proximal promoter and coding region are entirely contained within a CpG island, and are also spanned by an overlapping transcript, Sox2Ot, which contains $m m u$-miR1897 (Amaral et al., 2009; Shahryari et al., 2014), we developed a novel conditional by inversion Sox $2^{\text {COIN }}$ allele (Mandalos et al., 2012). The inverted COIN Sox2 allele (Sox $2^{I N V}$ ) is functionally null (Mandalos et al., 2012), as Sox $2^{I N V / I N V}$ mutants recapitulate the phenotype of Sox $2^{\beta g e o / \beta g e o}$ (Avilion et al., 2003a), Sox $2^{\beta g e o 2 / \beta g e o 2}$ (Ekonomou et al., 2005) and Sox $2^{\text {EpINV/ } / \beta g e o 2}$ (Mandalos et al., 2012) embryos, which die around implantation.
We generated epiblast inverted Sox $2^{E p I N V /+}$ mice, making use of the $\operatorname{Tg}$ (Sox2-CRE) mouse line that exerts efficient Cremediated recombination in the epiblast, but not in extraembryonic tissues (Hayashi et al., 2002a,b, 2003; Vincent and Robertson, 2003). Excision of the floxed sequences by $\operatorname{Tg}$ (Sox2-CRE) mice efficiently results in the visualization of eGFP in the epiblast at E6.5 (Figures 1A-D).

As Sox2 is known to function as a cell fate determinant (Kondo and Raff, 2004; Yamaguchi et al., 2011; Karnavas et al., 2013), we harvested embryos from various intercrosses at the onset of organogenesis (E11.5). Initially, we performed Sox $2^{\text {EpINV/+ }}$ $\mathrm{x}$ So $2^{+/+}$intercrosses and found that heterozygous E11.5 Sox $2^{E P I N V /+}$ embryos do not show any obvious abnormalities and are indistinguishable from control Sox $2^{\text {COIN/COIN }}$ and Sox $2^{+/+}$
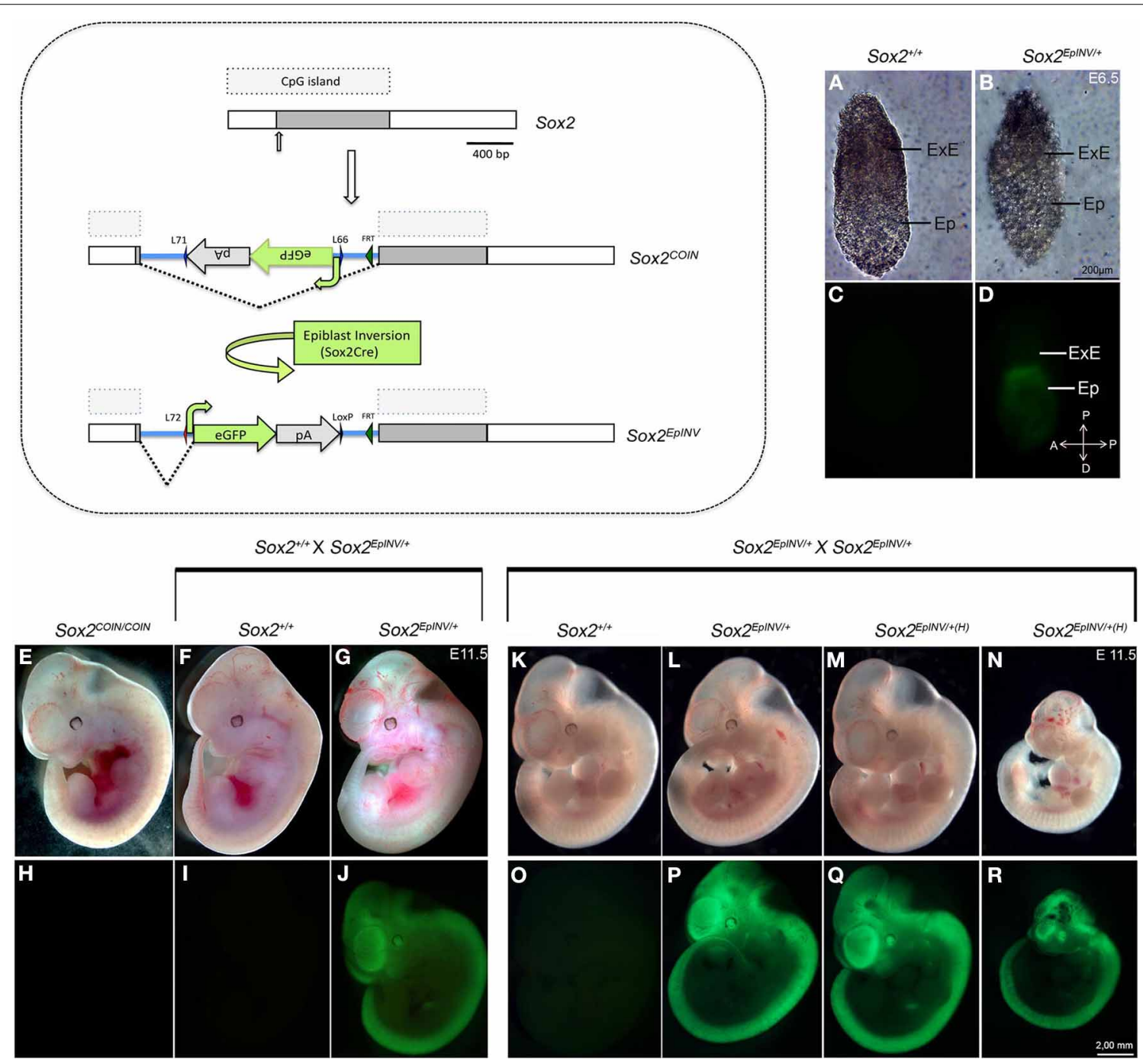

FIGURE 1 | Sox2 inversion in the epiblast leads to embryonic lethality at E11.5. Generation of the epiblast-inverted Sox $2^{\text {Ep/NV }}$ allele. Sox $2^{\text {Ep/NV } /+}$ embryos at E6.5 show normal morphology compared with Sox $2^{+/+}$control embryos. eGFP expression indicates that Sox2 is highly expressed in the epiblast, but not in the extraembryonic tissue (A-D). Sox $2^{\text {Ep/NV/+ }}$ embryos obtained from Sox2 EpINV/+ $\times$ Sox $2^{+/+}$intercrosses are normal. At E11.5,
Sox2 COIN/COIN and Sox $2^{E p I N V /+}$ embryos are indistinguishable from Sox $2^{+/+}$ littermates (E-J). Sox2 Ep/NV/+ intercrosses generate normal (Sox2Ep/NV/+) (K,L,O,P) and haploinsufficient $\left(\right.$ Sox $\left.2^{E p / N V /+(H)}\right)$ embryos (M,N, $\left.\mathbf{Q}, \mathbf{R}\right) .50 \%$ of the haploinsufficient Sox2 ${ }^{E p / N V /+(H)}$ embryos have normal size (M, $\left.\mathbf{0}\right)$, whereas the remaining ones have a smaller size $(\mathbf{N}, \mathbf{R})$ at E11.5. Both types of Sox $2^{E p / N V /+(H)}$ mutant embryos show evident defects in the head region $(\mathbf{M}, \mathbf{N})$. 
littermates (Figures 1E-G). E11.5 Sox $2^{\text {EpINV/+ embryos express }}$ eGFP precisely in the areas where Sox2 is expressed (Avilion et al., 2003a; Mandalos et al., 2012) (Figures 1H-J). Sox $2^{\text {EpINV/+ }}$ adult mice are fertile, feed normally, have normal body weight and normal lifespan, whilst Sox $2^{I N V /+}$ adult male exhibit no infertility problems, as some Sox $2^{\beta g e o /+}$ mice reportedly have (Avilion et al., 2003b). It is tempting to suggest that infertility problems in Sox $2^{\beta g e o 2 /+}$ and Sox $2^{\beta g e o 2 /+}$ mice could arise from the removal of regulatory regions due to the design of the mutants, while in Sox $2^{E p I N V /+}$ mice the whole sequence of the locus remains intact after inversion (Mandalos et al., 2012).

\section{EPIBLAST DELETION OF SoX2 RESULTS INTO HYDROCEPHALY AND CRANIOFACIAL DEFECTS}

We then proceeded to Sox $2^{E p I N V /+}$ intercrosses and harvested the embryos again at E11.5 (Table 1). Normally, if all Sox $2^{E P I N V /+}$ and Sox $2^{E P I N V / E p I N V}$ embryos would survive, one would expect that $75 \%$ of the embryos would be eGFPpositive $\left(\mathrm{eGFP}^{+}\right)$. However, we observed that only $48.8 \%$ of the embryos harvested were $\mathrm{eGFP}^{+}$, suggesting that as previously observed (Mandalos et al., 2012), the Sox2 EpINV/EpINV die in the deciduas at an early stage (Table 1). Half of the harvested $\mathrm{eGFP}^{+}$heterozygote embryos had normal phenotypes Sox $2^{E p I N V /+}$ (Figures 1L,P), while the remaining ones represented haploinsufficient Sox $2^{E D I N V /+}\left(\operatorname{Sox} 2^{E p I N V /+(\mathrm{H})}\right)$ mutants (Figures 1Q,R). The Sox $2^{E p I N V /+(\mathrm{H})}$ observed embryonic phenotypes fall in two categories: (a) $\operatorname{Sox} 2^{I N V /+(\mathrm{H})}$ embryos with a similar size to Sox $2^{+/+}$and Sox $2^{I N V /+}$ embryos (Figures 1M,Q) and (b) Sox $2^{I N V /+(\mathrm{H})}$ embryos with a significantly reduced size (Figures 1N,R) compared to Sox $2^{+/+}$(Figures 1K,O) and Sox $2^{E p I N V /+}$ littermates (Figures 1L,P). Sox $2^{E p I N V /+(\mathrm{H})}$ embryos exhibit heart defects, hemorrhage, bulging fourth ventricular roof, and severe craniofacial defects (Figure $\mathbf{1 M}$ ). We harvested litters at E12.5 and E15.5 derived from Sox $2^{E p I N V /+}$ intercrosses and found only Sox $2^{+/+}$and Sox $2^{E P I N V /+}$ normal embryos, suggesting that $\operatorname{Sox} 2^{E p I N V /+(\mathrm{H})}$ embryos die at around E11. Phenotypic differences among heterozygote Sox $2^{E p I N V /+}$ and Sox $2^{E P I N V /+(H)}$ littermates, derived from Sox $2^{E P I N V /+}$ intercrosses confirm that there is a Sox2 expression threshold, below which phenotypic abnormalities appear during embryogenesis. To generate conditional epiblast-inverted Sox2 mutants, we performed Sox $2^{\text {COIN/COIN }}$ to Sox $2^{\text {EpINV/+}}$; Tg(Sox2CRE) intercrosses and named these conditional mutant embryos Sox $2^{E p I N V / m o s a i c}$. We could harvest Sox $2^{E p I N V / m o s a i c}$ embryos from E8.5 to E11.5, but not beyond E11.5, indicating that these mutants, similarly to Sox $2^{E p I N V /+(\mathrm{H})}$ mutants, die around E11.5. Sox $2^{E p I N V / m o s a i c}$ embryos exhibited similar, albeit more severe, abnormalities compared to $\operatorname{Sox} 2^{E p I N V /+(\mathrm{H})}$ embryos (Figures 2A-F).

To examine whether a regional loss of Sox 2 expression was responsible for those defects, we analyzed Sox 2 expression by RNA in situ hybridization (Figures 2D-F). Sox2 was absent throughout the spinal cord (sc) in E10.5 mutants, with an exception of the tail tip of both Sox $2^{E P I N V /+}$ and Sox $2^{\text {EpINV/mosaic mutants }}$ (Figures 2E,F). However, there were no obvious morphological defects in the SC at E10.5, suggesting that down-regulation of Sox 2 could be rescued due to the functional redundancy of Sox2 with other SoxB genes, namely Sox1 and Sox3 (Uwanogho et al., 1995; Rex et al., 1997; Wood and Episkopou, 1999; Archer et al., 2011; Elkouris et al., 2011). We observed a down-regulation of Sox2 in the frontonasal process (fnp), the forebrain region ( $\mathrm{fb}$ ), the midbrain (mb) and the hindbrain (hb), the eye (Hever et al., 2006) and the otocyst (ot) (Kiernan et al., 2005; Hume et al., 2007; Pan et al., 2013) of Sox $2^{\text {EpINV/+(H) }}$ and Sox $2^{\text {EpINV/mosaic mutant }}$ embryos. Morphologically, there was a distortion of the eye, an enlargement of the brain ventricles, and marked translucency in the hindbrain region.

Several studies have shown that regulation of EMT during NCC development plays a crucial role for the normal development of the frontonasal region, including the palate and nasal cavities (Kang and Svoboda, 2005). We observed that Sox2 protein marks specific brain and craniofacial regions during their development (Figure 3). In E11.5 embryos, expression is seen in the hindbrain and forebrain neuroepithelium, and in the oral epithelium (Figures 3A-D). At E15.5, Sox2 is expressed in the dermis surrounding developing hair follicles and whiskers, including in their dermal papilla (Figures $\mathbf{3 H}-\mathbf{J}$ ). Sox 2 is also detected in the epithelium of the retina (Figure 3K), in developing bone and cartilage (Figure 3L), in muscle fibers (Figures 3M,N) and the acinar structures of the salivary glands (Figure 30). Furthermore, Sox2 asymmetrically marks the epithelium that connects the developing molar teeth with the oral epithelium (Figure 3P). At later post-natal stages Sox 2 is expressed in the alveolar bone (ab) (Figure 3T) and in the incisor labial cervical loop (cl, Figures 3R,S). In the hair follicles the expression is confined to some cells of the inner and outer sheath (Figures 3Q,U).

To further analyze the craniofacial defects observed in Sox $2^{\text {EpINV/+(H) }}$ embryos, we harvested E11.5 Sox $2^{E p I N V /+(H)}$ mutants and sectioned them for hematoxylin and eosin histological analysis (Figures 4A-D). Compared to Sox $2^{+/+}$

Table 1 | Analysis of progeny from Sox ${ }^{E p I N V /+} \times$ Sox $2^{E p I N V /+}$ intercrosses"

\begin{tabular}{|c|c|c|c|c|c|c|}
\hline \multicolumn{7}{|c|}{ Genotypic distribution obtained at E11.5* } \\
\hline Total & Dead & Live & Sox $2^{E p I N V /+}$ & Sox $2^{E p / N V /+(H)}$ & Sox2 $2^{E p / N V / E p I N V}$ & Sox $2^{+/+}$ \\
\hline 43 & $11(25.6 \%)$ & $32(74.4 \%)$ & $11(25.6 \%)$ & $10(23.2)^{* *}$ & $0(0 \%)$ & $11(25.6 \%)$ \\
\hline
\end{tabular}




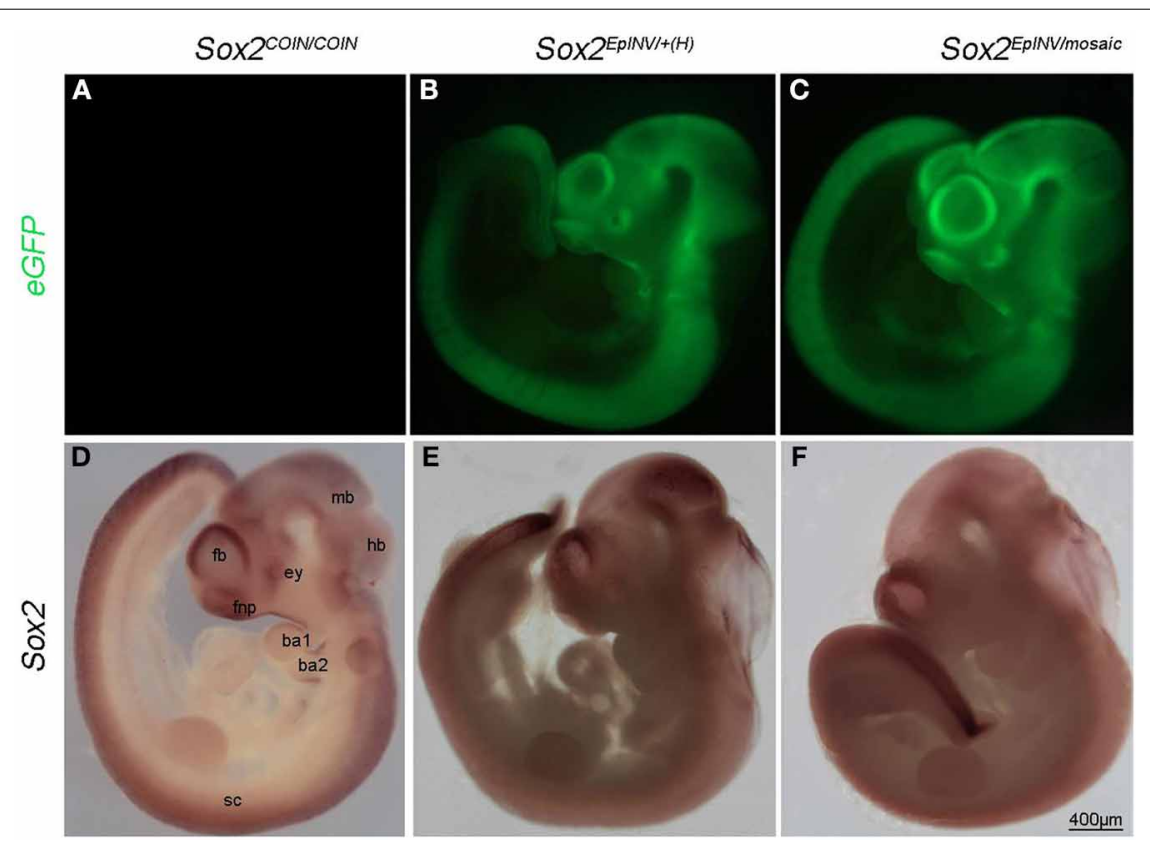

FIGURE 2 | Sox2 loss leads to multiple developmental defects. eGFP expression recapitulates the expression of Sox2 in Sox2 Ep/NV/mosaic mutant (A-C). Whole mount in situ hybridization shows down-regulation of Sox2 in the hindbrain (hb), midbrain (mb) and forebrain ( $\mathrm{fb}$ ) regions, in the frontonasal process (fnp), the eye (ey), the surface ectoderm of branchial arches 1 and 2 (ba1, ba2), and the spinal cord (sc) but not the tail tip, of E10.5 Sox $2^{E p / N V /+(H)}$ and Sox $2^{E p / N V / m o s a i c}$ embryos. These embryos show increased translucency mostly visible at the level of the hindbrain (hb); forebrain ( $\mathrm{fb}$ ) and midbrain (mb). Ventricles are also enlarged and frontonasal truncations are evident (D-F). normal embryos, we observed a reduction of the thickness of the neuroepithelial wall lining the telencephalic ( $\mathrm{fb})$, mesencephalic $(\mathrm{mb})$ and rhombencephalic (hb) ventricles, defective frontonasal proccess and oral cavity formation, and dilated lumen of the optic stalk (Figures 4A-D). Thus, Sox2 loss leads to severe brain and craniofacial defects.

\section{SOX2 LOSS LEADS TO DOWN-REGULATION OF HoXa2 IN RHOMBOMERE 3, BUT NOT HOXb1 IN RHOMBOMERE 4}

In order to find out whether Sox2 loss of function disrupts the Hox code in hindbrain, we analyzed the expression of Hoxa2

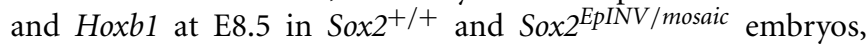
using whole mount in situ hybridization (Figures 5A,B). We observed that Hoxa2 is down-regulated in rhombomere (r)3, but not in $\mathrm{r} 5$ of Sox $2^{\text {EpINV/mosaic }}$ mutant embryos, underscoring a specific role for Sox2 in the regulation of Hoxa2 in $\mathrm{r} 3$ at E8.5 (Figures 5A,B). To find out whether Sox2 loss of function affects the facial innervation programme, we analyzed the expression of Hoxb1 in Sox $2^{+/+}$and Sox $2^{\text {EpINV/mosaic embryos, and found }}$ that Hoxb1 expression was unaffected both in $\mathrm{r} 4$ (Figures 5A,B) and in the spinal cord (data not shown) of E8.5 Sox2 EpINV/mosaic embryos. Thus, our results do not support previous reports on Sox2 involvement in the regulation of Hoxb1 in vitro, at least with regard to E8.5 hindbrain and spinal cord regions. As predicted from these observations, when cranial nerves were stained for Sox10 expression at E11.5 in mutant embryos (Figures 5C,D), we found that Sox2 loss of function does not affect the formation of Sox $10^{+}$ganglia of the spinal accessory, vagus (n10), glossopharyngeal (n9), and branches of facial (n7) nerves (Figures 5C,D).

\section{Sox2 FINE-TUNES THE FLOW OF MIGRATING Sox10+ NCCs}

To investigate the fate of NCCs that may under to craniofacial abnormalities observed in Sox2 mutants, we analyzed Sox10 expression in Sox $2^{+/+}$and Sox $2^{E p I N V /+(\mathrm{H})}$ embryos at E9.5, at an embryonic stage in which Sox $10^{+}$NCCs are migrating along the lateral surface of the neural tube in wild-type embryos. We found that Sox $10^{+}$cells expressing high levels of Sox10 are heterotopically present in the frontonasal region and in the branchial arches (ba) 1-2 of Sox $2^{E p I N V /+(H)}$ mutants (Figure 5A). Thus, down-regulation of Sox 2 causes a dramatic up-regulation of Sox10 expression and an outflow of Sox $10^{+}$cells in the hindbrain (hb) and branchial areas of mutant embryos. Furthermore, we observed Sox $10^{+}$cells in Sox2 $2^{\text {E INV/+(H) }}$ mutant embryos in frontonasal areas, where Sox10 is normally not expressed, while migrating CNCC do not express Sox10 at this embryonic stage in Sox $2^{+1+}$ control embryos (Figures 6A-D). Thus, Sox2 loss disrupts severely the CNCC development.

\section{DISCUSSION}

EMT plays a crucial role in the development of the embryonic head (Mitsiadis, 2011). CNCCs undergo EMT and individual cells delaminate from the lateral ridges of the dorsal neural tube and migrate to the craniofacial area (Kouskoura et al., 2011) to form the frontonasal, maxillary and mandibular processes (BronnerFraser, 2002). Amongst genes of the SoxB1 group (Sox1-3), which are predominantly expressed in the developing central nervous system (CNS) (Collignon et al., 1996; Wood and Episkopou, 1999), Sox3 activity is required for pharyngeal segmentation and for the pharyngeal epithelium to proceed toward craniofacial 

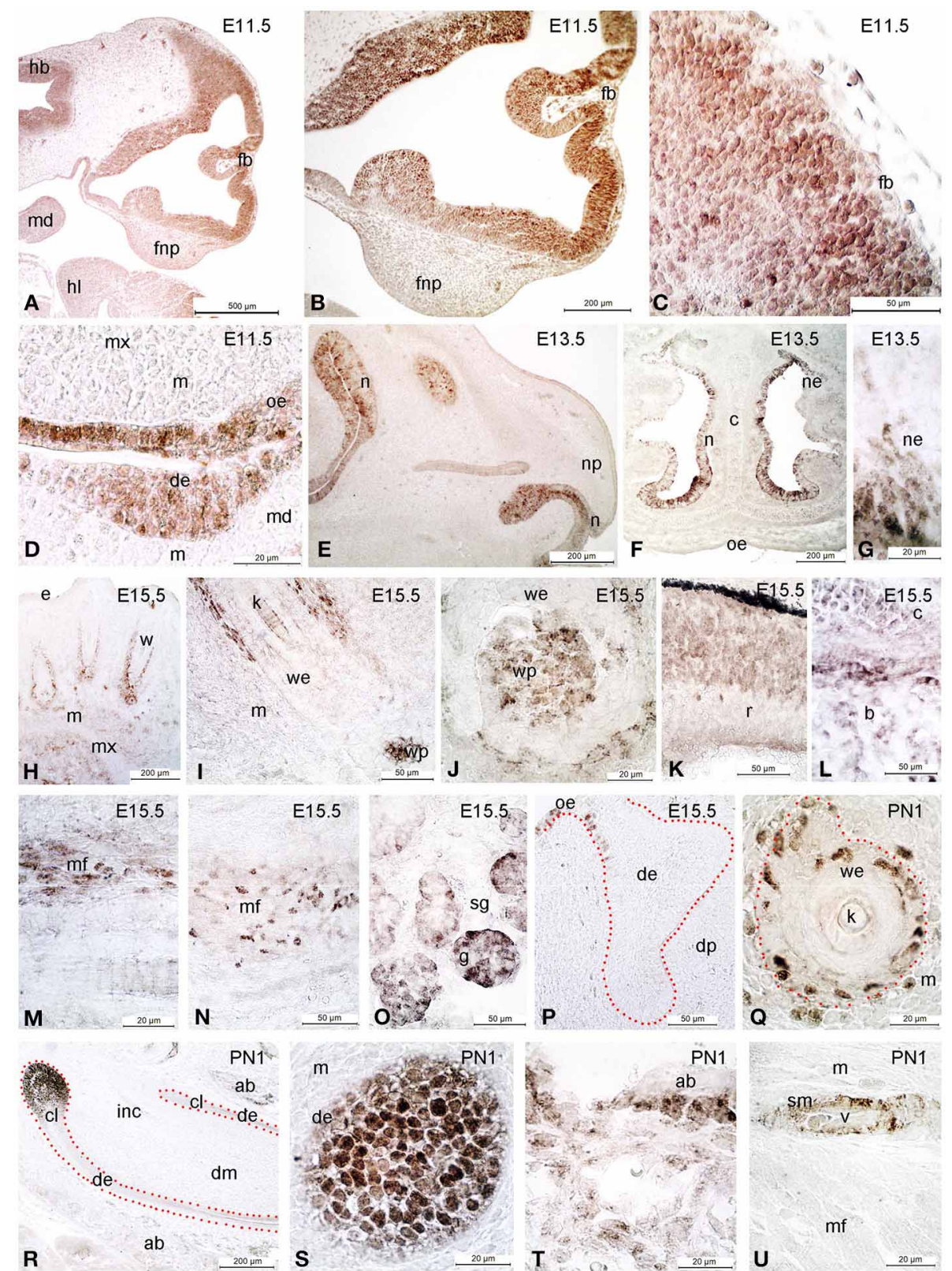

FIGURE 3 | Immunohistochemical analysis of Sox2 expression in developing craniofacial structures. At E11.5 Sox2 is detected in hindbrain (hb) and forebrain (fb), as well as in the oral epithelium (oe) (A-D). At E13.5, expression appears in the nasal epithelium (ne) (E-G). At E15.5 Sox2 is expressed in the dermis surrounding the developing whiskers (w), and in their dermal papilla (wp) (H-P). Expression is also detected in the retina $(r, \mathbf{K})$, in developing bone (b) and cartilage $(\mathbf{c}, \mathbf{L})$, in developing muscle fibers $(\mathrm{mf}, \mathbf{M}, \mathbf{N})$, and in salivary glands $(\mathrm{sg}, \mathbf{O})$. Noteworthy, the expression of Sox2 in the developing molar teeth is asymmetrical, being restricted to the connection between the tooth and the oral epithelium (oe) along the lingual side (P). At postnatal day 1 (PN1), Sox2 expression is limited to some cells of the inner and outer root sheath of the whisker epithelium (we, the outer root sheath being delimited by red dots, $\mathbf{Q}$ ) (Q-U). Sox2 is furthermore expressed in the labial cervical loop (cl) of the incisor (inc) (R,S), in the alveolar bone (ab) $(\mathbf{T}, \mathbf{S})$ and the vasculature (U). de, dental epithelium; dm, dental mesenchyme; dp, dental papilla; fnp, frontonasal process; hl, hindlimb; $\mathrm{m}$, mesenchyme; $\mathrm{md}$, mandible; $\mathrm{mx}$, maxilla; $n$, nose; $n p$, nasal process; e, epithelium; g, glomerulae; $k$, keratinized part of the whisker; $v$, vessel; sm, smooth muscle; sg, salivary gland; c, cartilage; $r$, retina; $f$, follicle; $m f$, muscular fibers. morphogenesis (Rizzoti and Lovell-Badge, 2007). On the other hand, Sox2 activity has been implicated in processes that counteract NCC development (Hutton and Pevny, 2011; Remboutsika et al., 2011; Cimadamore et al., 2012) and could affect the generation of NCC progeny, as observed in differentiation experiments of human ES cells (ESC)-derived NCCs into sensory neurons in vitro (Cimadamore et al., 2012). Thus, the severity of defects observed in the developing brain and facial structures 


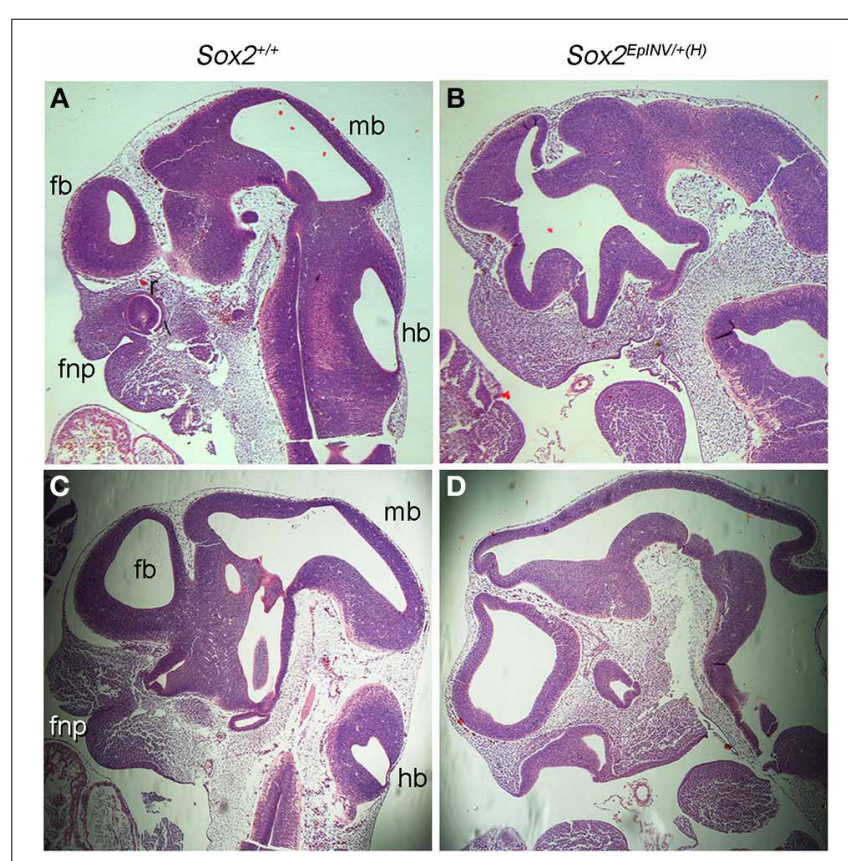

FIGURE 4 | Sox $2^{I N V /+(H)}$ E11.5 embryos exhibit brain and craniofacial malformations. Histological analysis of Sox $2^{+/+}$and Sox $2^{E p / N V /+(H)}$ embryos head structures (A-D). Serial sagittal sections of E11.5 embryos stained with hematoxylin and eosin. Sox $2^{E p / N V /+(H)}$ embryos exhibit thinness of the ventricular wall and abnormal oral cavity formation enlarged forebrain and midbrain ventricles, while the frontonasal process ( $\mathrm{fnp}$ ) is severely reduced with an abnormal oral cavity $(\mathbf{B}, \mathbf{D})$ when compared Sox $2^{+/+}$littermates $(\mathbf{A}, \mathbf{C})$.

of Sox $2^{E p I N V /+(H)}$ and Sox $2^{\text {EpINV/mosaic }}$ mutants underline a Sox2 dosage-dependent role in the development of both the head and craniofacial areas.

Sox $2^{E P I N V /+(H)}$ and Sox $2^{E p I N V / m o s a i c}$ embryos suffer from ventriculomegaly, which in turn leads to the accumulation of increased amounts of cerebrospinal fluid (CSF) in the brain. Hydrocephaly involves both dilated ventricular system and increased intracranial pressure. Every reduction in the thickness of the ventricular wall invevitably will result in dilation of the ventricular system (hydrocephalus ex vacuo). It is difficult to establish cause and effect relationship in this reciprocal setting, however abnormal brain wall development will definitely lead to morphologically enlarged ventricular system. The indication that the ventricular system is enlarged could not in itself be considered proof of hydrocephaly, because there is thickness of the wall, thus pointing to ventriculomegaly only (Deveale et al., 2013). Likewise, reduction in the diameter of the aqueduct and abnormal periaqueductal region development does not prove etiological relationship toward hydrocephalus causation (Lee et al., 2012). In adult animals, hydrocephaly involves also defects in choroid plexus, but as this is in very early stages in development at the embryonic period we examined, the contribution of CSF overproduction in hydrocephalus causation is hard

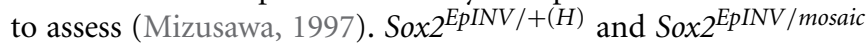
mutants display developmental defects both in ventricular system/wall formation, as well as in the oral cavity morphology
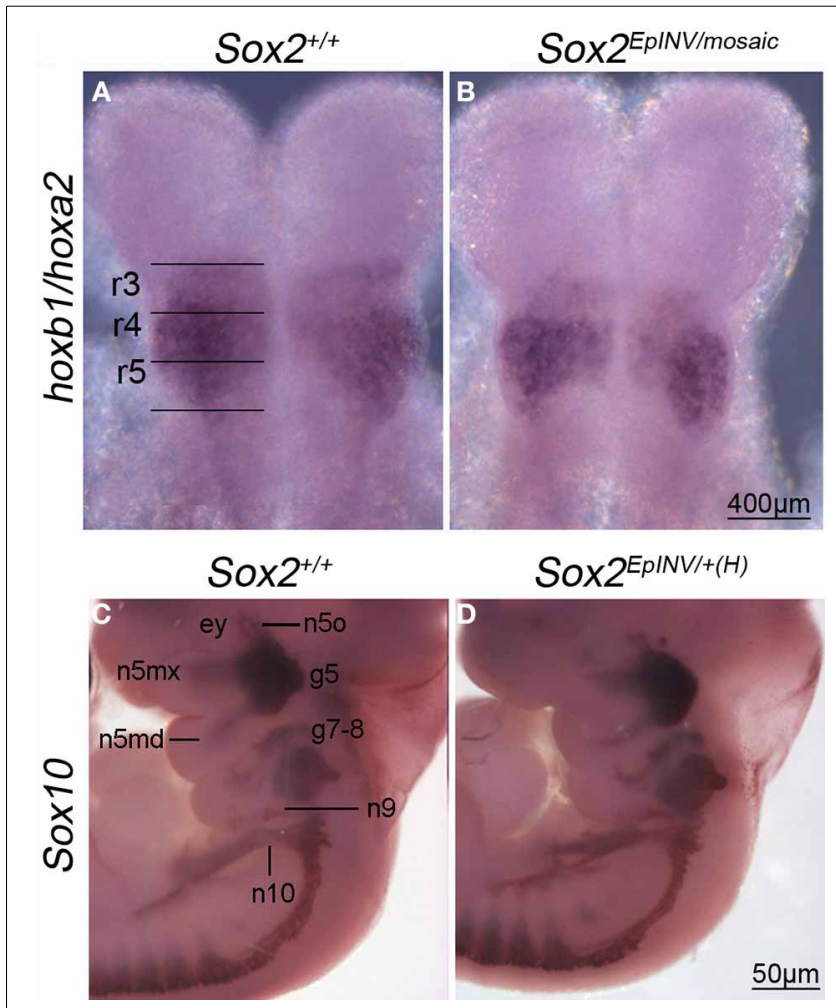

FIGURE 5 | Hoxa2 and Hoxb1 expression in rhombomeres, and Sox10 expression in developing cranial nerves and ganglia. In situ hybridization for Hoxa2 and Hoxb1 at E8.5 reveals that Hoxa2 is down-regulated in rhombomere 3 of a Sox $2^{I N V / m o s a i c}$ embryo, but not in rhombomere $5(\mathbf{A}, \mathbf{B})$. Hoxb1 is normally expressed in $\mathrm{r} 4$ in Sox $2^{1 \mathrm{NV} / \text { mosaic }}$ mutants (A,B). Sox $10^{+}$nerves form normally in Sox $2^{E p / N V /+(H)}$ embryos. In situ hybridization reveals that Sox10 expression is not affected in branchial arches 1 and 2 (ba1, ba2) in developing cranial nerves and ganglia ( $10, \mathrm{n} 9, \mathrm{n} 5 \mathrm{mx}, \mathrm{n} 5 \mathrm{md}, \mathrm{g7}-8, \mathrm{~g} 5, \mathrm{n} 5 \mathrm{o})$ of Sox2 Ep/NV/mosaic mutants compared with Sox $2^{+/+}$control embryos (C,D). ey, eye.

that could contribute to early pathoanatomical events resulting in hydrocephalus and craniofacial defects in humans (Panetta et al., 2008). Thus, disruption of Sox 2 function in the embryonic head region could be an additional cause for the development of hydrocephalus later on in life.

Hox genes play an essential role in the development of craniofacial structures (Trainor and Krumlauf, 2000; Narita and Rijli, 2009; Tumpel et al., 2009; Di Bonito et al., 2013). At E8.5, Hoxbl is expressed in $\mathrm{r} 4$ and throughout the spinal cord region (Gavalas et al., 2003), where it is required for the specification of facial branchiomotor neuron progenitors that are programmed to innervate the facial muscles (Arenkiel et al., 2004). Despite the fact that Sox2 has been shown to regulate Hoxb1 in vitro (Di Rocco et al., 2001; Williams et al., 2004; Lian et al., 2010), the expression of Hoxb1 appeared to be unaffected both in $\mathrm{r} 4$ and in the spinal cord of E8.5 Sox $2^{I N V / m o s a i c}$ embryos (Figure 4). Our results do not support previous reports on Sox2 involvement in the regulation of Hoxb1 in vitro, at least with regard to E8.5 hindbrain and spinal cord regions. On the other hand, Hoxa2 appears to be down-regulated in our mutants. At E8.5, Hoxa2 has a limit of expression in the rhombencephalic neural tube corresponding to 


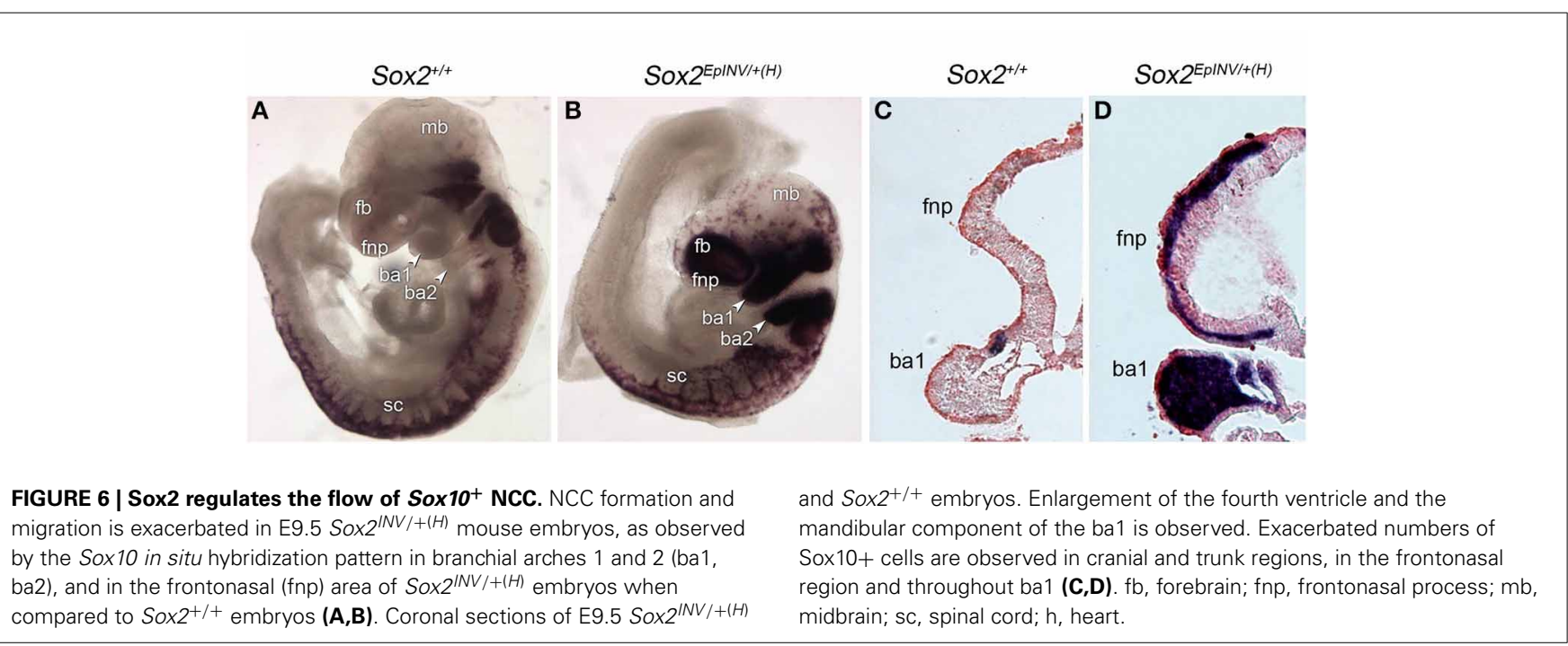

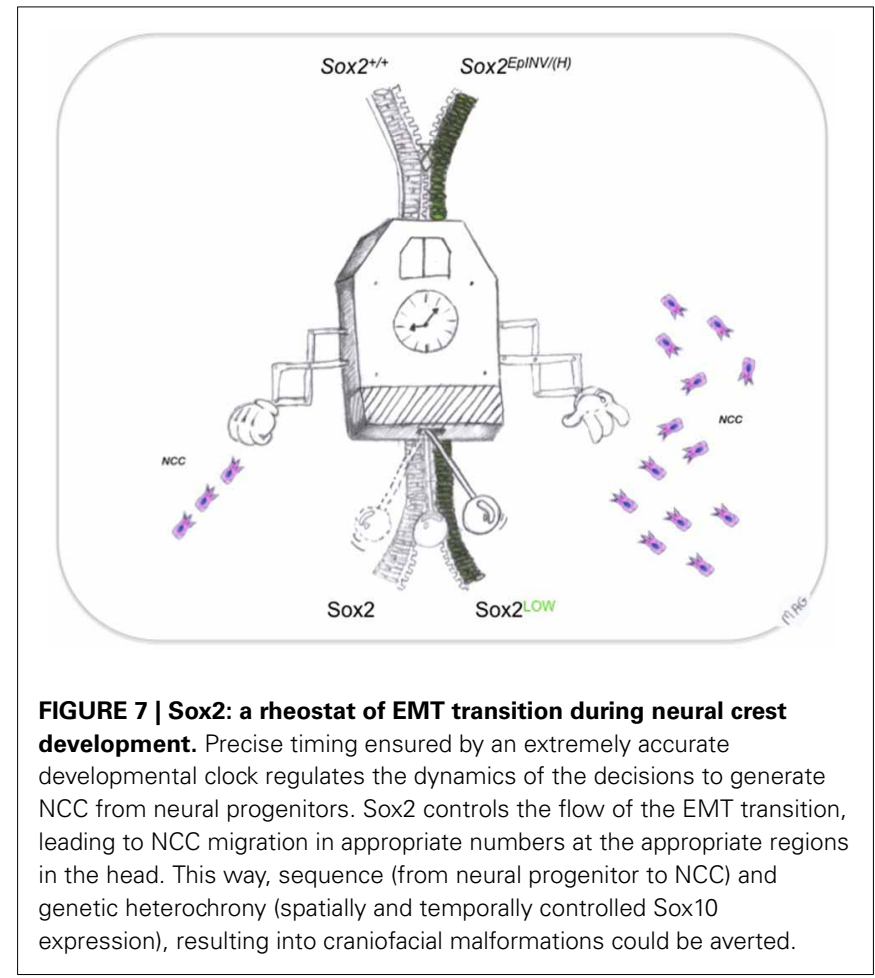

r3 and r5 (Prince and Lumsden, 1994). It is not surprising that no effect was observed in Hoxa2 expression in $\mathrm{r} 5$, as Sox 2 is expressed along the hindbrain in all rhombomeres, but not in $\mathrm{r} 5$ (Wood and Episkopou, 1999). Hoxa2-null mutant embryos lack craniofacial and cartilage elements derived from the first and second branchial arch and die perinatally due to cleft palate (Vieille-Grosjean et al., 1997; Rijli et al., 1998; Trainor and Krumlauf, 2001; Santagati et al., 2005). Sox2 has been shown to interact in vitro with a SoxB DNA binding element (ACAAT motif) present in the enhancer of the Hoxa2 gene and mutation of this motif reduces the expression of a Hoxa2 reporter in electroporation experiments in chick embryo hindbrains (Tumpel et al., 2008). The reduction of Hoxa2 expression in Sox2 EpINV mutants indicates that Sox2 controls an integral component of NCC morphogenetic program, which requires Hoxa2 at discrete time points to pattern distinct derivatives in craniofacial structures (Santagati et al., 2005).

As neural progenitor cells differentiate into NCCs, a switch in expression from SoxB to SoxE genes becomes evident, with Sox2 inactivated in the NCC progenitors, whereas Sox 9 and Sox 10 are activated in newly migrating trunk NCCs (Melton et al., 2004; Remboutsika et al., 2011). This is a necessary switch for the activation of the complex mechanism that generates NCCs (Wakamatsu et al., 2004). Amongst the SoxE genes, Sox10 is required for the formation, maintenance of multipotency, specification and differentiation of NCCs (Kelsh, 2006). Sox10 is the only SoxE gene that maintains its expression during migration of NCCs along the lateral surface of the neural tube (McKeown et al., 2005), except in the cranial region. Sox10 mutations lead to several craniofacial abnormalities in humans, called neurocristopathies, including Waardenburg-Hirschsprung syndrome and peripheral neuropathies (Hoke, 2012). Sox2 over-expression and Sox ${ }^{+}$neural stem cell transplantation experiments in avian and murine cranial neural tubes have demonstrated that Sox2 restricts neuroepithelial differentiation into CNCCs (Cheung and Briscoe, 2003; Remboutsika et al., 2011; Wahlbuhl et al., 2012). Thus, the exacerbation of Sox $10^{+}$migrating cells in the Sox $2^{E P I N V}$ mutants may not be surprising. These observations point out that Sox 2 could act to repress Sox10 expression. However, any genetic interaction between Sox 2 and Sox 10 in neural progenitor or NCC progenitor cells is far from evident in vivo and in vitro. Whether Sox 2 could influence the expression of Sox10 directly or indirectly by affecting levels of other SoxE genes such as Sox8 and Sox9 that contribute to the induction of Sox10 in NCC progenitors, once NC-inducing signals are set (Taylor and Labonne, 2005; McCauley and Bronner-Fraser, 2006; Haldin and Labonne, 2010; Stolt and Wegner, 2010; Wahlbuhl et al., 2012), remains to be investigated. In the Sox $2^{\text {EPINV }}$ mutants, Sox 10 levels appear dramatically increased both in the branchial arches area and in the frontonasal area. Sox10 over-expression has been shown to arrest the neuroepithelial and cranial mesenchymal cells in an 
undifferentiated state, causing a range of cell fate specification defects (Ahlstrom and Erickson, 2009). Neural progenitor cells, which over-express Sox10 remain undifferentiated and fail to form neuronal, Schwann, or melanocyte cells (Stolt et al., 2008). Thus, it is tempting to suggest that the failure of the embryos to form the craniofacial region could, in part, be due to the failure of the cranial mesenchyme to proceed through development due to an aberrant and exacerbated population of Sox $10^{+}$cells in the frontonasal region.

In recent years, the importance of NCCs as inducers of peripheral neural structures, craniofacial tissues and other peripheral mesodermal-derived structures has become evident (Trainor and Tam, 1995; Trainor et al., 2003; Hong and Saint-Jeannet, 2005; Cordero et al., 2011; Hagiwara et al., 2014). Defects in their development has been attributed to a failure and/or abnormal NCCs migration and differentiation (Bronner, 2012), resulting into the generation of neurocristopathies in humans (Etchevers et al., 2006) and expanding the most recent classification of neurocristopathies to an entire category of abnormal induction of non-neural NCC-derived peripheral structures of the body (Cossais et al., 2010). Recent evidence has shown that Sox2 has been indirectly associated with defects that are characteristic of the CHARGE syndrome, a human neurocristopathy (Aramaki et al., 2007). CHARGE syndrome patients exhibited mutations in the Chd7 gene (Vallaster et al., 2012), the product of which acts as a Sox2 transcriptional cofactor (Engelen et al., 2011; Puc and Rosenfeld, 2011). Our results suggest a Sox2 dosage-dependent mechanism acting during head development, with a specific role for Sox 2 in the prevention of these CNCC-related pathologies. We propose that Sox2 acts as a rheostat of EMT during CNCC development that influences cell fates involved in head development (Figure 7). These findings open novel avenues to target Sox2 in a number of craniofacial malformations in humans.

\section{ACKNOWLEDGMENTS}

The authors thank Brigitte Schuhbaur for excellent technical assistance and Maria-Angeliki Gavala for the design of the model. Eumorphia Remboutsika and Nikolaos Mandalos were supported by the "Bilateral cooperation grant" (NON-EU82) funded by National grants from the Ministry of Development, cofinanced by the European Union and Greek operational program "Competitiveness and Enterpreneurship" European Regional Development Fund (NSFR 2007-2013), the "Synergasia grant" (09-SYN66-12), the ADiSC - Thalis Grant funded by Framework Program "Education and Lifelong Learning," co-financed by the European Commission (European Social Fund) and National funds from the Ministry of Education. This work was performed under the auspices of a research collaboration agreement with REGENERON Pharmaceuticals Inc., New York, USA. Thimios Mitsiadis and Zoraide Granchi were supported by a SNSF grant (09-SYN66-12) and from UZH. Muriel Rhinn and Pascal Dollé were supported by an Agence Nationale de la Recherche grant (ReSiNeS-SVSE2-2011).

\section{REFERENCES}

Ahlstrom, J. D., and Erickson, C. A. (2009). New views on the neural crest epithelial-mesenchymal transition and neuroepithelial interkinetic nuclear migration. Commun. Integr. Biol. 2, 489-493. doi: 10.4161/cib.2.6.9406
Akitaya, T., and Bronner-Fraser, M. (1992). Expression of cell adhesion molecules during initiation and cessation of neural crest cell migration. Dev. Dyn. 194, 12-20. doi: 10.1002/aja.1001940103

Amaral, P. P., Neyt, C., Wilkins, S. J., Askarian-Amiri, M. E., Sunkin, S. M., Perkins, A. C., et al. (2009). Complex architecture and regulated expression of the Sox2ot locus during vertebrate development. RNA 15, 2013-2027. doi: 10.1261/rna.1705309

Aquino, J. B., Hjerling-Leffler, J., Koltzenburg, M., Edlund, T., Villar, M. J., and Ernfors, P. (2006). In vitro and in vivo differentiation of boundary cap neural crest stem cells into mature Schwann cells. Exp. Neurol. 198, 438-449. doi: 10.1016/j.expneurol.2005.12.015

Aramaki, M., Kimura, T., Udaka, T., Kosaki, R., Mitsuhashi, T., Okada, Y., et al. (2007). Embryonic expression profile of chicken CHD7, the ortholog of the causative gene for CHARGE syndrome. Birth Defects Res. A Clin. Mol. Teratol. 79, 50-57. doi: 10.1002/bdra.20330

Archer, T. C., Jin, J., and Casey, E. S. (2011). Interaction of Sox1, Sox2, Sox3 and Oct4 during primary neurogenesis. Dev. Biol. 350, 429-440. doi: 10.1016/j.ydbio.2010.12.013

Arenkiel, B. R., Tvrdik, P., Gaufo, G. O., and Capecchi, M. R. (2004). Hoxb1 functions in both motoneurons and in tissues of the periphery to establish and maintain the proper neuronal circuitry. Genes Dev. 18, 1539-1552. doi: $10.1101 /$ gad. 1207204

Avilion, A. A., Nicolis, S. K., Pevny, L. H., Perez, L., Vivian, N., and Lovell-Badge, R. (2003a). Multipotent cell lineages in early mouse development depend on SOX2 function. Genes Dev. 17, 126-140. doi: 10.1101/gad.224503

Avilion, A. A., Nicolis, S. K., Pevny, L. H., Perez, L., Vivian, N., and Lovell-Badge, R. (2003b). Multipotent cell lineages in early mouse development depend on SOX2 function. Genes Dev. 17, 126-140. doi: 10.1101/gad.224503

Aybar, M. J., Glavic, A., and Mayor, R. (2002). Extracellular signals, cell interactions and transcription factors involved in the induction of the neural crest cells. Biol. Res. 35, 267-275. doi: 10.4067/S0716-97602002000200018

Aybar, M. J., and Mayor, R. (2002). Early induction of neural crest cells: lessons learned from frog, fish and chick. Curr. Opin. Genet. Dev. 12, 452-458. doi: 10.1016/S0959-437X(02)00325-8

Ayer-Le Lievre, C. S., and Le Douarin, N. M. (1982). The early development of cranial sensory ganglia and the potentialities of their component cells studied in quail-chick chimeras. Dev. Biol. 94, 291-310. doi: 10.1016/00121606(82)90349-9

Bernard, P., and Harley, V. R. (2010). Acquisition of SOX transcription factor specificity through protein-protein interaction, modulation of Wnt signalling and post-translational modification. Int. J. Biochem. Cell Biol. 42, 400-410. doi: 10.1016/j.biocel.2009.10.017

Betancur, P., Sauka-Spengler, T., and Bronner, M. (2011). A Sox10 enhancer element common to the otic placode and neural crest is activated by tissue-specific paralogs. Development 138, 3689-3698. doi: 10.1242/dev.057836

Bowles, J., Schepers, G., and Koopman, P. (2000). Phylogeny of the SOX family of developmental transcription factors based on sequence and structural indicators. Dev. Biol. 227, 239-255. doi: 10.1006/dbio.2000.9883

Briscoe, C. P., Tadayyon, M., Andrews, J. L., Benson, W. G., Chambers, J. K., Eilert, M. M., et al. (2003). The orphan G protein-coupled receptor GPR40 is activated by medium and long chain fatty acids. J. Biol. Chem. 278, 11303-11311. doi: 10.1074/jbc.M211495200

Bronner, M. E. (2012). Formation and migration of neural crest cells in the vertebrate embryo. Histochem. Cell Biol. 138, 179-186. doi: 10.1007/s00418012-0999-z

Bronner-Fraser, M. (2002). Molecular analysis of neural crest formation. J. Physiol. Paris 96, 3-8. doi: 10.1016/S0928-4257(01)00074-2

Cardiff, R. D., Miller, C. H., and Munn, R. J. (2014). Manual hematoxylin and eosin staining of mouse tissue sections. Cold Spring Harb. Protoc. 2014, 655-658. doi: 10.1101/pdb.prot073411

Cheng, Y., Cheung, M., Abu-Elmagd, M. M., Orme, A., and Scotting, P. J. (2000). Chick sox10, a transcription factor expressed in both early neural crest cells and central nervous system. Brain Res. Dev. Brain Res. 121, 233-241. doi: 10.1016/S0165-3806(00)00049-3

Cheung, M., and Briscoe, J. (2003). Neural crest development is regulated by the transcription factor Sox9. Development 130, 5681-5693. doi: 10.1242/dev. 00808

Chotteau-Lelievre, A., Dolle, P., and Gofflot, F. (2006). Expression analysis of murine genes using in situ hybridization with radioactive and nonradioactively 
labeled RNA probes. Methods Mol. Biol. 326, 61-87. doi: 10.1385/1-59745007-3:61

Christiansen, A. E., Keisman, E. L., Ahmad, S. M., and Baker, B. S. (2002). Sex comes in from the cold: the integration of sex and pattern. Trends Genet. 18, 510-516. doi: 10.1016/S0168-9525(02)02769-5

Cimadamore, F., Shah, M., Amador-Arjona, A., Peran, E. M., Chen, C., and Terskikh, A. V. (2012). SOX2 Modulates levels of MITF in human embryonic stem cell - derived neural crest, normal human melanocytes, and melanoma lines in vitro. Pigment Cell Melanoma Res. 25, 533-536. doi: 10.1111/j.1755148X.2012.01012.x

Collignon, J., Sockanathan, S., Hacker, A., Cohen-Tannoudji, M., Norris, D., Rastan, S., et al. (1996). A comparison of the properties of Sox-3 with Sry and two related genes, Sox-1 and Sox-2. Development 122, 509-520.

Cordero, D. R., Brugmann, S., Chu, Y., Bajpai, R., Jame, M., and Helms, J. A. (2011). Cranial neural crest cells on the move: their roles in craniofacial development. Am. J. Med. Genet. A 155A, 270-279. doi: 10.1002/ajmg.a.33702

Cossais, F., Wahlbuhl, M., Kriesch, J., and Wegner, M. (2010). SOX10 structurefunction analysis in the chicken neural tube reveals important insights into its role in human neurocristopathies. Hum. Mol. Genet. 19, 2409-2420. doi: $10.1093 / \mathrm{hmg} / \mathrm{ddq} 124$

Del Barrio, M. G., and Nieto, M. A. (2002). Overexpression of Snail family members highlights their ability to promote chick neural crest formation. Development 129, 1583-1593.

Deveale, B., Brokhman, I., Mohseni, P., Babak, T., Yoon, C., Lin, A., et al. (2013). Oct4 is required $\sim$ E7.5 for proliferation in the primitive streak. PLoS Genet. 9:e1003957. doi: 10.1371/journal.pgen.1003957

Di Bonito, M., Glover, J. C., and Studer, M. (2013). Hox genes and region-specific sensorimotor circuit formation in the hindbrain and spinal cord. Dev. Dyn. 242, 1348-1368. doi: 10.1002/dvdy.24055

Dickinson, M. E., Selleck, M. A., McMahon, A. P., and Bronner-Fraser, M. (1995). Dorsalization of the neural tube by the non-neural ectoderm. Development 121, 2099-2106.

Di Rocco, G., Gavalas, A., Popperl, H., Krumlauf, R., Mavilio, F., and Zappavigna, V. (2001). The recruitment of SOX/OCT complexes and the differential activity of HOXA1 and HOXB1 modulate the Hoxb1 auto-regulatory enhancer function. J. Biol. Chem. 276, 20506-20515. doi: 10.1074/jbc.M011175200

Dottori, M., Gross, M. K., Labosky, P., and Goulding, M. (2001). The winged-helix transcription factor Foxd3 suppresses interneuron differentiation and promotes neural crest cell fate. Development 128, 4127-4138.

Ekonomou, A., Kazanis, I., Malas, S., Wood, H., Alifragis, P., Denaxa, M., et al. (2005). Neuronal migration and ventral subtype identity in the telencephalon depend on SOX1. PLoS Biol. 3:e186. doi: 10.1371/journal.pbio. 0030186

Elkouris, M., Balaskas, N., Poulou, M., Politis, P. K., Panayiotou, E., Malas, S., et al. (2011). Soxl maintains the undifferentiated state of cortical neural progenitor cells via the suppression of Proxl-mediated cell cycle exit and neurogenesis. Stem Cells 29, 89-98. doi: 10.1002/stem.554

Endo, T., Nakagawa, T., Lee, J. E., Dong, Y., Kim, T. S., Iguchi, F., et al. (2002). Alteration in expression of p27 in auditory epithelia and neurons of mice during degeneration. Neurosci. Lett. 334, 173-176. doi: 10.1016/S0304-3940(02) 01115-1

Engelen, E., Akinci, U., Bryne, J. C., Hou, J., Gontan, C., Moen, M., et al. (2011). Sox 2 cooperates with Chd7 to regulate genes that are mutated in human syndromes. Nat. Genet. 43, 607-611. doi: 10.1038/ng.825

Etchevers, H. C., Amiel, J., and Lyonnet, S. (2006). Molecular bases of human neurocristopathies. Adv. Exp. Med. Biol. 589, 213-234. doi: 10.1007/978-0-38746954-6_14

Fischer, A. H., Jacobson, K. A., Rose, J., and Zeller, R. (2008). Hematoxylin and eosin staining of tissue and cell sections. CSH Protoc. 2008, pdb prot4986. doi: $10.1101 /$ pdb.prot4986

Gammill, L. S., and Bronner-Fraser, M. (2002). Genomic analysis of neural crest induction. Development 129, 5731-5741. doi: 10.1242/dev.00175

Gammill, L. S., and Bronner-Fraser, M. (2003). Neural crest specification: migrating into genomics. Nat. Rev. Neurosci. 4, 795-805. doi: 10.1038/nrn1219

Garcia-Castro, M. I., Marcelle, C., and Bronner-Fraser, M. (2002). Ectodermal Wnt function as a neural crest inducer. Science 297, 848-851. doi: 10.1126/science. 107824

Gavalas, A., Ruhrberg, C., Livet, J., Henderson, C. E., and Krumlauf, R. (2003). Neuronal defects in the hindbrain of Hoxa1, Hoxb1 and Hoxb2 mutants reflect regulatory interactions among these Hox genes. Development 130, 5663-5679. doi: $10.1242 /$ dev.00802

Graham, V., Khudyakov, J., Ellis, P., and Pevny, L. (2003). SOX2 functions to maintain neural progenitor identity. Neuron 39, 749-765. doi: 10.1016/S08966273(03)00497-5

Hagiwara, K., Obayashi, T., Sakayori, N., Yamanishi, E., Hayashi, R., Osumi, N., et al. (2014). Molecular and cellular features of murine craniofacial and trunk neural crest cells as stem cell-like cells. PLoS ONE 9:e84072. doi: 10.1371/journal.pone.0084072

Haldin, C. E., and Labonne, C. (2010). SoxE factors as multifunctional neural crest regulatory factors. Int. J. Biochem. Cell Biol. 42, 441-444. doi: 10.1016/j.biocel.2009.11.014

Hayashi, S., Lewis, P., Pevny, L., and McMahon, A. P. (2002a). Efficient gene modulation in mouse epiblast using a Sox2Cre transgenic mouse strain. Gene Expr. Patterns 2, 93-97. doi: 10.1016/S0925-4773(02)00292-7

Hayashi, S., Lewis, P., Pevny, L., and McMahon, A. P. (2002b). Efficient gene modulation in mouse epiblast using a Sox2Cre transgenic mouse strain. Mech. Dev. 119(Suppl. 1), S97-S101. doi: 10.1016/S0925-4773(03)00099-6

Hayashi, S., Tenzen, T., and McMahon, A. P. (2003). Maternal inheritance of Cre activity in a Sox2Cre deleter strain. Genesis 37, 51-53. doi: 10.1002/gene. 10225

Heeg-Truesdell, E., and Labonne, C. (2004). A slug, a fox, a pair of sox: transcriptional responses to neural crest inducing signals. Birth Defects Res. C Embryo Today 72, 124-139. doi: 10.1002/bdrc.20011

Hever, A. M., Williamson, K. A., and Van Heyningen, V. (2006). Developmental malformations of the eye: the role of PAX6, SOX2 and OTX2. Clin. Genet. 69, 459-470. doi: 10.1111/j.1399-0004.2006.00619.x

Hoke, A. (2012). Animal models of peripheral neuropathies. Neurotherapeutics 9, 262-269. doi: 10.1007/s13311-012-0116-y

Hong, C. S., and Saint-Jeannet, J. P. (2005). Sox proteins and neural crest development. Semin Cell Dev. Biol. 16, 694-703. doi: 10.1016/j.semcdb.2005.06.005

Huang, X., and Saint-Jeannet, J. P. (2004). Induction of the neural crest and the opportunities of life on the edge. Dev. Biol. 275, 1-11. doi: 10.1016/j.ydbio.2004.07.033

Hume, C. R., Bratt, D. L., and Oesterle, E. C. (2007). Expression of LHX3 and SOX2 during mouse inner ear development. Gene Expr. Patterns 7, 798-807. doi: 10.1016/j.modgep.2007.05.002

Hutton, S. R., and Pevny, L. H. (2011). SOX2 expression levels distinguish between neural progenitor populations of the developing dorsal telencephalon. Dev. Biol. 352, 40-47. doi: 10.1016/j.ydbio.2011.01.015

Jessel, A. S., and Weiss, P. L. (1998). Orthodox practices clarified. Am. J. Occup. Ther. 52, 71-72. doi: 10.5014/ajot.52.1.71d

Kamachi, M., Bruce, V., Mukaida, S., Gyoba, J., Yoshikawa, S., and Akamatsu, S. (2013). Dynamic properties influence the perception of facial expressions. Perception 42, 1266-1278. doi: 10.1068/p3131n

Kang, P., and Svoboda, K. K. (2005). Epithelial-mesenchymal transformation during craniofacial development. J. Dent. Res. 84, 678-690. doi: $10.1177 / 154405910508400801$

Karnavas, T., Mandalos, N., Malas, S., and Remboutsika, E. (2013). SoxB, cell cycle and neurogenesis. Front. Physiol. 4:298. doi: 10.3389/fphys.2013.00298

Kelsh, R. N. (2006). Sorting out Sox10 functions in neural crest development. Bioessays 28, 788-798. doi: 10.1002/bies.20445

Kiernan, A. E., Pelling, A. L., Leung, K. K., Tang, A. S., Bell, D. M., Tease, C., et al. (2005). Sox 2 is required for sensory organ development in the mammalian inner ear. Nature 434, 1031-1035. doi: 10.1038/nature03487

Knuchel, M. C., Graf, B., Schlaepfer, E., Kuster, H., Fischer, M., Weber, R., et al. (2000). PCR-derived ssDNA probes for fluorescent in situ hybridization to HIV1 RNA. J. Histochem. Cytochem. 48, 285-294. doi: 10.1177/002215540004800214

Kondo, T., and Raff, M. (2004). Chromatin remodeling and histone modification in the conversion of oligodendrocyte precursors to neural stem cells. Genes Dev. 18, 2963-2972. doi: 10.1101/gad.309404

Kos, R., Reedy, M. V., Johnson, R. L., and Erickson, C. A. (2001). The wingedhelix transcription factor FoxD3 is important for establishing the neural crest lineage and repressing melanogenesis in avian embryos. Development 128 , 1467-1479.

Kouskoura, T., Fragou, N., Alexiou, M., John, N., Sommer, L., Graf, D., et al. (2011). The genetic basis of craniofacial and dental abnormalities. Schweiz. Monatsschr. Zahnmed. 121, 636-646.

Labonne, C., and Bronner-Fraser, M. (1998). Induction and patterning of the neural crest, a stem cell-like precursor population. J. Neurobiol. 36, 175-189. 
Laga, A. C., Lai, C. Y., Zhan, Q., Huang, S. J., Velazquez, E. F., Yang, Q., et al. (2010). Expression of the embryonic stem cell transcription factor SOX2 in human skin: relevance to melanocyte and merkel cell biology. Am. J. Pathol. 176, 903-913. doi: 10.2353/ajpath.2010.090495

Le, N., Nagarajan, R., Wang, J. Y., Araki, T., Schmidt, R. E., and Milbrandt, J. (2005). Analysis of congenital hypomyelinating Egr2Lo/Lo nerves identifies Sox2 as an inhibitor of Schwann cell differentiation and myelination. Proc. Natl. Acad. Sci. U.S.A. 102, 2596-2601. doi: 10.1073/pnas.0407836102

Lee, K., Tan, J., Morris, M. B., Rizzoti, K., Hughes, J., Cheah, P. S., et al. (2012). Congenital hydrocephalus and abnormal subcommissural organ development in Sox3 transgenic mice. PLoS ONE 7:e29041. doi: 10.1371/journal. pone.0029041

Lian, P., Liu, L. A., Shi, Y., Bu, Y., and Wei, D. (2010). Tethered-hopping model for protein-DNA binding and unbinding based on Sox2-Oct1-Hoxb1 ternary complex simulations. Biophys. J. 98, 1285-1293. doi: 10.1016/j.bpj.2009.12.4274

Liem, K. F. Jr., Tremml, G., Roelink, H., and Jessell, T. M. (1995). Dorsal differentiation of neural plate cells induced by BMP-mediated signals from epidermal ectoderm. Cell 82, 969-979. doi: 10.1016/0092-8674(95)90276-7

Liu, J. P., and Jessell, T. M. (1998). A role for rhoB in the delamination of neural crest cells from the dorsal neural tube. Development 125, 5055-5067.

Mandalos, N., Saridaki, M., Harper, J. L., Kotsoni, A., Yang, P., Economides, A. N., et al. (2012). Application of a novel strategy of engineering conditional alleles to a single exon gene, Sox2. PLoS ONE 7:e45768. doi: 10.1371/journal.pone. 0045768

McCauley, D. W., and Bronner-Fraser, M. (2006). Importance of SoxE in neural crest development and the evolution of the pharynx. Nature 441, 750-752. doi: 10.1038 /nature04691

McKeown, S. J., Lee, V. M., Bronner-Fraser, M., Newgreen, D. F., and Farlie, P. G. (2005). Sox10 overexpression induces neural crest-like cells from all dorsoventral levels of the neural tube but inhibits differentiation. Dev. Dyn. 233, 430-444. doi: 10.1002/dvdy.20341

Melton, K. R., Iulianella, A., and Trainor, P. A. (2004). Gene expression and regulation of hindbrain and spinal cord development. Front. Biosci. 9, 117-138. doi: $10.2741 / 1202$

Mitsiadis, T. A. (2011). Everything is on the head. Front. Physiol. 2:2. doi: 10.3389/fphys.2011.00002

Mizusawa, H. (1997). [Corticobasal degeneration]. Rinsho Shinkeigaku 37, 1131-1133.

Monier, R. (1995). [Cell transformation]. Rev. Prat. 45, 1867-1872.

Nakagawa, S., and Takeichi, M. (1995). Neural crest cell-cell adhesion controlled by sequential and subpopulation-specific expression of novel cadherins. Development 121, 1321-1332.

Narita, Y., and Rijli, F. M. (2009). Hox genes in neural patterning and circuit formation in the mouse hindbrain. Curr. Top. Dev. Biol. 88, 139-167. doi: 10.1016/S0070-2153(09)88005-8

Nie, X., Luukko, K., and Kettunen, P. (2006). BMP signalling in craniofacial development. Int. J. Dev. Biol. 50, 511-521. doi: 10.1387/ijdb.052101xn

Pan, H., and Schultz, R. M. (2011). Sox 2 modulates reprogramming of gene expression in two-cell mouse embryos. Biol. Reprod. 85, 409-416. doi: 10.1095/biolreprod.111.090886

Pan, W., Jin, Y., Chen, J., Rottier, R. J., Steel, K. P., and Kiernan, A. E. (2013). Ectopic expression of activated notch or SOX2 reveals similar and unique roles in the development of the sensory cell progenitors in the mammalian inner ear. J. Neurosci. 33, 16146-16157. doi: 10.1523/JNEUROSCI.3150-12.2013

Panetta, N. J., Gupta, D. M., Slater, B. J., Kwan, M. D., Liu, K. J., and Longaker, M. T. (2008). Tissue engineering in cleft palate and other congenital malformations. Pediatr. Res. 63, 545-551. doi: 10.1203/PDR.0b013e31816a743e

Papanayotou, C., Mey, A., Birot, A. M., Saka, Y., Boast, S., Smith, J. C., et al. (2008). A mechanism regulating the onset of Sox 2 expression in the embryonic neural plate. PLoS Biol. 6:e2. doi: 10.1371/journal.pbio.0060002

Pevny, L. H., and Lovell-Badge, R. (1997). Sox genes find their feet. Curr. Opin. Genet. Dev. 7, 338-344. doi: 10.1016/S0959-437X(97)80147-5

Placzek, M., and Briscoe, J. (2005). The floor plate: multiple cells, multiple signals. Nat. Rev. Neurosci. 6, 230-240. doi: 10.1038/nrn1628

Prince, V., and Lumsden, A. (1994). Hoxa-2 expression in normal and transposed rhombomeres: independent regulation in the neural tube and neural crest. Development 120, 911-923.

Puc, J., and Rosenfeld, M. G. (2011). SOX2 and CHD7 cooperatively regulate human disease genes. Nat. Genet. 43, 505-506. doi: 10.1038/ng.843
Remboutsika, E., Elkouris, M., Iulianella, A., Andoniadou, C. L., Poulou, M., Mitsiadis, T. A., et al. (2011). Flexibility of neural stem cells. Front. Physiol. 2:16. doi: 10.3389/fphys.2011.00016

Rex, M., Orme, A., Uwanogho, D., Tointon, K., Wigmore, P. M., Sharpe, P. T., et al. (1997). Dynamic expression of chicken Sox 2 and Sox 3 genes in ectoderm induced to form neural tissue. Dev. Dyn. 209, 323-332.

Rhinn, M., Schuhbaur, B., Niederreither, K., and Dolle, P. (2011). Involvement of retinol dehydrogenase 10 in embryonic patterning and rescue of its loss of function by maternal retinaldehyde treatment. Proc. Natl. Acad. Sci. U.S.A. 108, 16687-16692. doi: 10.1073/pnas.1103877108

Rijli, F. M., Gavalas, A., and Chambon, P. (1998). Segmentation and specification in the branchial region of the head: the role of the Hox selector genes. Int. J. Dev. Biol. 42, 393-401.

Rizzoti, K., and Lovell-Badge, R. (2007). SOX3 activity during pharyngeal segmentation is required for craniofacial morphogenesis. Development 134, 3437-3448. doi: 10.1242/dev.007906

Rutishauser, U., and Jessell, T. M. (1988). Cell adhesion molecules in vertebrate neural development. Physiol. Rev. 68, 819-857.

Santagati, F., Minoux, M., Ren, S. Y., and Rijli, F. M. (2005). Temporal requirement of Hoxa2 in cranial neural crest skeletal morphogenesis. Development 132, 4927-4936. doi: 10.1242/dev.02078

Scherson, T., Serbedzija, G., Fraser, S., and Bronner-Fraser, M. (1993). Regulative capacity of the cranial neural tube to form neural crest. Development 118, 1049-1062.

Selleck, M. A., and Bronner-Fraser, M. (1995). Origins of the avian neural crest: the role of neural plate-epidermal interactions. Development 121, 525-538.

Shahryari, A., Ra Ee, M. R., Fouani, Y., Alipour, N., Samaei, N. M., Shafiee, M., et al. (2014). Two novel splice variants of SOX2OT, SOX2OT-S1 and SOX2OTS2, Are Co-upregulated with SOX2 and OCT4 in Esophageal Squamous Cell Carcinoma. Stem Cells 32, 126-134. doi: 10.1002/stem.1542

Stolt, C. C., Lommes, P., Friedrich, R. P., and Wegner, M. (2004). Transcription factors Sox 8 and Sox 10 perform non-equivalent roles during oligodendrocyte development despite functional redundancy. Development 131, 2349-2358. doi: 10.1242/dev.01114

Stolt, C. C., Lommes, P., Hillgartner, S., and Wegner, M. (2008). The transcription factor Sox 5 modulates Sox 10 function during melanocyte development. Nucleic Acids Res. 36, 5427-5440. doi: 10.1093/nar/gkn527

Stolt, C. C., and Wegner, M. (2010). SoxE function in vertebrate nervous system development. Int. J. Biochem. Cell Biol. 42, 437-440. doi: 10.1016/j.biocel.2009.07.014

Taneyhill, L. A. (2008). To adhere or not to adhere: the role of Cadherins in neural crest development. Cell Adh. Migr. 2, 223-230. doi: 10.4161/cam.2. 4.6835

Taylor, K. M., and Labonne, C. (2005). SoxE factors function equivalently during neural crest and inner ear development and their activity is regulated by SUMOylation. Dev. Cell 9, 593-603. doi: 10.1016/j.devcel.2005. 09.016

Trainor, P. A., and Krumlauf, R. (2000). Patterning the cranial neural crest: hindbrain segmentation and Hox gene plasticity. Nat. Rev. Neurosci. 1, 116-124. doi: $10.1038 / 35039056$

Trainor, P. A., and Krumlauf, R. (2001). Hox genes, neural crest cells and branchial arch patterning. Curr. Opin. Cell Biol. 13, 698-705. doi: 10.1016/S09550674(00)00273-8

Trainor, P. A., Melton, K. R., and Manzanares, M. (2003). Origins and plasticity of neural crest cells and their roles in jaw and craniofacial evolution. Int. J. Dev. Biol. 47, 541-553.

Trainor, P. A., and Tam, P. P. (1995). Cranial paraxial mesoderm and neural crest cells of the mouse embryo: co-distribution in the craniofacial mesenchyme but distinct segregation in branchial arches. Development 121, 2569-2582.

Tumpel, S., Cambronero, F., Sims, C., Krumlauf, R., and Wiedemann, L. M. (2008). A regulatory module embedded in the coding region of Hoxa 2 controls expression in rhombomere 2. Proc. Natl. Acad. Sci. U.S.A. 105, 20077-20082. doi: 10.1073/pnas.0806360105

Tumpel, S., Wiedemann, L. M., and Krumlauf, R. (2009). Hox genes and segmentation of the vertebrate hindbrain. Curr. Top. Dev. Biol. 88, 103-137. doi: 10.1016/S0070-2153(09)88004-6

Uwanogho, D., Rex, M., Cartwright, E. J., Pearl, G., Healy, C., Scotting, P. J., et al. (1995). Embryonic expression of the chicken Sox2, Sox3 and Sox11 genes 
suggests an interactive role in neuronal development. Mech. Dev. 49, 23-36. doi: 10.1016/0925-4773(94)00299-3

Vallaster, M., Vallaster, C. D., and Wu, S. M. (2012). Epigenetic mechanisms in cardiac development and disease. Acta Biochim. Biophys. Sin. 44, 92-102. doi: 10.1093/abbs/gmr090

Vieille-Grosjean, I., Hunt, P., Gulisano, M., Boncinelli, E., and Thorogood, P. (1997). Branchial HOX gene expression and human craniofacial development. Dev. Biol. 183, 49-60. doi: 10.1006/dbio.1996.8450

Villanueva, S., Glavic, A., Ruiz, P., and Mayor, R. (2002). Posteriorization by FGF, Wnt, and retinoic acid is required for neural crest induction. Dev. Biol. 241, 289-301. doi: 10.1006/dbio.2001.0485

Vincent, S. D., and Robertson, E. J. (2003). Highly efficient transgene-independent recombination directed by a maternally derived SOX2CRE transgene. Genesis 37, 54-56. doi: 10.1002/gene.10226

Wahlbuhl, M., Reiprich, S., Vogl, M. R., Bosl, M. R., and Wegner, M. (2012). Transcription factor Sox10 orchestrates activity of a neural crest-specific enhancer in the vicinity of its gene. Nucleic Acids Res. 40, 88-101. doi: 10.1093/nar/gkr734

Wakamatsu, Y., Endo, Y., Osumi, N., and Weston, J. A. (2004). Multiple roles of Sox2, an HMG-box transcription factor in avian neural crest development. Dev. Dyn. 229, 74-86. doi: 10.1002/dvdy.10498

Wegner, M. (1999). From head to toes: the multiple facets of Sox proteins. Nucleic Acids Res. 27, 1409-1420. doi: 10.1093/nar/27.6.1409

Wen, J., Hu, Q., Li, M., Wang, S., Zhang, L., Chen, Y., et al. (2008). Pax6 directly modulate Sox2 expression in the neural progenitor cells. Neuroreport 19, 413-417. doi: 10.1097/WNR.0b013e3282f64377

Williams, D. C. Jr., Cai, M., and Clore, G. M. (2004). Molecular basis for synergistic transcriptional activation by Oct1 and Sox 2 revealed from the solution structure of the 42-kDa Oct1.Sox2.Hoxb1-DNA ternary transcription factor complex. J. Biol. Chem. 279, 1449-1457. doi: 10.1074/jbc.M3097 90200
Wilson, M., and Koopman, P. (2002). Matching SOX: partner proteins and cofactors of the SOX family of transcriptional regulators. Curr. Opin. Genet. Dev. 12, 441-446. doi: 10.1016/S0959-437X(02)00323-4

Wood, H. B., and Episkopou, V. (1999). Comparative expression of the mouse Soxl, Sox 2 and Sox 3 genes from pre-gastrulation to early somite stages. Mech. Dev. 86, 197-201. doi: 10.1016/S0925-4773(99)00116-1

Wu, J., Saint-Jeannet, J. P., and Klein, P. S. (2003). Wnt-frizzled signaling in neural crest formation. Trends Neurosci. 26, 40-45. doi: 10.1016/S01662236(02)00011-5

Yamaguchi, S., Hirano, K., Nagata, S., and Tada, T. (2011). Sox2 expression effects on direct reprogramming efficiency as determined by alternative somatic cell fate. Stem Cell Res. 6, 177-186. doi: 10.1016/j.scr.2010.09.004

Conflict of Interest Statement: The authors declare that the research was conducted in the absence of any commercial or financial relationships that could be construed as a potential conflict of interest.

Received: 18 July 2014; accepted: 22 August 2014; published online: 12 September 2014. Citation: Mandalos N, Rhinn M, Granchi Z, Karampelas I, Mitsiadis T, Economides AN, Dollé P and Remboutsika E (2014) Sox2 acts as a rheostat of epithelial to mesenchymal transition during neural crest development. Front. Physiol. 5:345. doi: 10.3389/fphys.2014.00345

This article was submitted to Craniofacial Biology, a section of the journal Frontiers in Physiology.

Copyright (c) 2014 Mandalos, Rhinn, Granchi, Karampelas, Mitsiadis, Economides, Dolle and Remboutsika. This is an open-access article distributed under the terms of the Creative Commons Attribution License (CC BY). The use, distribution or reproduction in other forums is permitted, provided the original author(s) or licensor are credited and that the original publication in this journal is cited, in accordance with accepted academic practice. No use, distribution or reproduction is permitted which does not comply with these terms. 